\title{
ANALYSIS OF CHROMOSOMAL DAMAGE CAUSED BY ACETAMIPRID
}

\author{
Stupáková, K., Galdíková, M., Schwarzbacherová, V., Holečková, B. \\ Department of Biology and Genetics, Institute of Genetics \\ University of Veterinary Medicine and Pharmacy, Komenského 73, 04181 Košice \\ Slovakia \\ martina.galdikova@uvlf.sk
}

\section{ABSTRACT}

Different chemicals can have genotoxic effects on the body, as confirmed by chromosome damage detection. Using conventional cytogenetic analysis and fluorescence in situ hybridization, we tested the extent of chromosome damage caused by the acetamiprid-based insecticide Mospilan 20SP on bovine peripheral blood lymphocytes at concentrations of, 2.5, 5, 25 and $50 \mu \mathrm{g} \cdot \mathrm{ml}^{-1}$ after a $24 \mathrm{~h}$ incubation period. During the experiment, the presence of unstable aberrations-chromosomal and chromatid breaks and gaps-were detected by conventional cytogenetic analysis. With increasing insecticide concentrations, we observed a statistically significant increase in chromosome damage frequency after 24 hours of exposure. Fluorescence in situ hybridization was used to detect stable structural aberrations; whole-chromosome painting probes for bovine chromosomes 1 and 7 (BTA 1 and BTA 7) were used for this purpose. As a result of exposure to the insecticide, neither BTA 1/BTA 7 translocations nor other types of translocations were observed.
Key words: acetamiprid; conventional cytogenetic analysis; chromosomal aberrations; fluorescence in situ hybridization

\section{INTRODUCTION}

Within the growing human population and its higher demands for food, not only on the quantity but also on the sensory and physical properties, there are increasing requirements on agriculture and safety criteria concerning pesticides [4].

Intensive use of pesticides leads to environmental contamination. It directly affects the soil, water flows, groundwater, non-target organisms, and last but not least, can affect the animal and human health by careless and improper use [7]. In livestock, there is a decline in performance and consequently, high economic losses for breeders. Also the decreasing populations of honey bees are also associated with the use of pesticides. In a study by Doublet et al. [5], microbial pathogens (with which pesticides can interact and worsen their effect on bee colonies) were tested. 
A non-nicotinic pesticide thiacloprid was used at sublethal doses with two common microbial pathogens (Nosema ceranae and BQCV-maternal blackening virus) affected the larvae and adult bees. The interaction of the neonicotinoid with the pathogens resulted in the increased mortality of both larvae and adult bees.

In our experiments, we investigated Mospilan 20SP (containing the active substance of $20 \%$ acetamiprid) which belongs to the systemically acting insecticides of the neonicotinoid group. The acetamiprid is spread throughout the plant, passing into the nectar. It acts neurotoxically, thus blocking the nicotinic receptor in the postsynaptic membrane in the nervous system of the pests. The mechanism of action consists in blocking postsynaptic nicotinic acetylcholine receptors (nAChRs) of the insect, disrupting pulse transmission, thereby gradually causing paralysis and consequently, death [9]. Neonicotinoids are much more toxic to invertebrates such as insects than to mammals, birds, and other higher organisms because they directly attack their central nervous system, in which the $\mathrm{AChRs}$ are located [6].

Acetamiprid is one of the most widely used insecticides in recent decades. Together with fipronil, neonicotinoids account for a third of the world's insecticide market. The benefits of their physicochemical properties, low target organism resistance and low user risk, have resulted in a high percentage of use. They can now be detected in soil, water and air [15]. Acetamiprid has a wide spectrum of action on animal pests, which can be used for seedlings, stoneworms, cereals, potatoes, vegetables and even ornamental plants. Pests sensitive to this insecticide are mainly: Aphis pomi, Eriosomala nigerium, Leptinotarsa decimlineata, Sitobion avenae, Metopolphium dirhodum, Brevicory nebrassicae, Aphis gossypii, Trialerodes vaporarium and others. It is highly harmful to aquatic organisms with a long-term residual effect.

Chromosome aberrations (CA) are any changes in the number or structure of chromosomes. They may be induced spontaneously or result from exposure to genotoxic agents [13]. Chromosome aberrations are a microscopically visible part of a broad spectrum of DNA changes generated by double-stranded DNA breaks (DSBs). DSBs are initial lesions in the CA formation process. They can lead to various disorders in mammals and are the result of cancerous exogenous agents: such as free pollution radicals, radiomimetic compounds, pesticides and radiation. DSBs grow progressively at significant frequencies during cellular processes and after exposure to ionizing radiation, by the action of specific drugs, pesticides, or endonucleases. If DNA is not incorrectly repaired, DSBs can lead to a chromosome break. Double-stranded DNA breaks may lead to mutation, chromosomal rearrangements, and oncogenic transformations. Signal networks that respond to DNA damage activate a complicated DNA repair system and induce cell cycle arrest to ensure proper repair of any transient damage. In the case of irreversible DNA damage, apoptosis is initiated to prevent further spread of damaged genetic material to future generations of cells [2]. Testing agents for their ability to induce chromosome aberrations have an important role in mutagenic and screening detection strategies of carcinogenic agents. Several studies have shown a correlation between elevated CA in peripheral blood lymphocytes and an increased risk of cancer onset. Many types of cancer are associated with specific types of CA [1].

In our study we focused on verifying the potential genotoxic effects of the pesticide acetamiprid (Mospilan 20SC) using conventional cytogenetic analysis to detect unstable aberrations and supplemented by fluorescence in situ hybridization to detect stable and numerical aberrations of chromosomes.

\section{MATERIALS AND METHODS}

In our study, two healthy intact male bovine bulls were used, from which peripheral blood was collected from the vena jugularis into sterile heparinized tubes. By conventional cytogenetic analysis, we observed unstable structure aberrations in the peripheral blood lymphocytes of bulls at negative (water) and positive control (ethyl methanesulfonate, EMS, Sigma, St. Louis, MO, USA, $250 \mu \mathrm{g} \cdot \mathrm{ml}^{-1}$ ) as well as at, 2.5, 5, 25 and $50 \mu \mathrm{g} \cdot \mathrm{ml}^{-1}$ of acetamiprid (Mospilan 20SC) concentration after 24 hours of incubation.

Structural aberrations were evaluated in 100 metaphases for each donor and concentration. The value of the mitotic index was determined by the calculation from the number of metaphases per total number of 1000 cells. The statistical significance of the effects of the insecticide on the induction of chromosomal aberrations and reduction of mitotic index in lymphocytes of bovine peripheral blood was determined by parametric $\chi 2$ test. The standard deviations (SD) were calculated using variation analysis. 
Fluorescence in situ hybridization at a concentration of $25 \mu \mathrm{g} \cdot \mathrm{ml}^{-1}$ of acetamiprid in peripheral blood lymphocytes after $24 \mathrm{~h}$ culture was used to detect stable structural aberrations using whole-chromosome probes for the labelling of chromosomes 1 and 7 (BTA 1, BTA 7). The results of hybridization were evaluated and recorded under a fluorescence microscope Nikon (Labophot 2A/2) through dual filters.

\section{RESULTS}

In conventional cytogenetics, the spontaneous frequency of aberrations in donor 1 was at $1 \%$ and $2 \%$ in donor 2 . After the exposure to the pesticide, we recorded an increase in the structure aberration frequencies with increasing concentrations of acetamiprid. The highest percentage of breaks were observed in donor 1 at $25 \mu \mathrm{g} \cdot \mathrm{ml}^{-1}(\mathrm{P}<0.001)$ and in donor 2 at $50 \mu \mathrm{g} \cdot \mathrm{ml}^{-1}(\mathrm{P}<0.01)$. The most common detectable types of aberrations were the chromatic breaks, along with chromosome breaks and gaps (Fig. 1).

In both donors, we observed a decrease in mitotic index with increasing concentrations of the pesticide. Statistically significant data in both donors were at $25 \mu \mathrm{g} \cdot \mathrm{ml}^{-1}$ and $50 \mu \mathrm{g} \cdot \mathrm{ml}^{-1}$ (Fig. 2).

The second method involved the use of fluorescent in situ hybridization to test the effect of acetamiprid on peripheral blood lymphocytes to detect stable and numerical aberrations. In our experiment we detected two polyploidy and no stable structural aberrations.

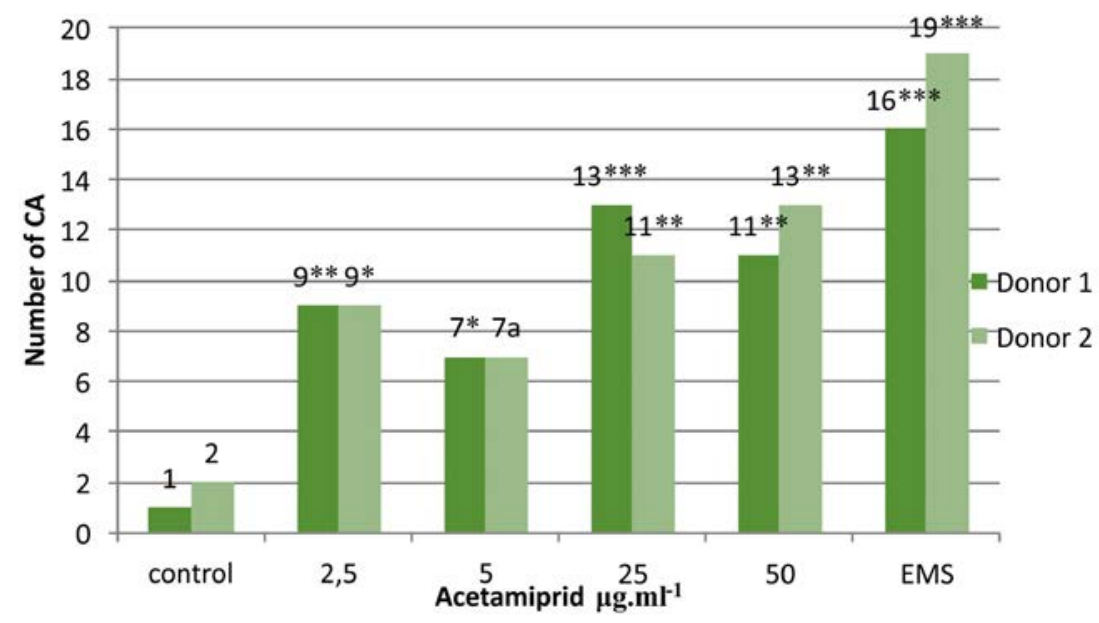

Fig. 1. Graphical representation of conventional cytogenetics results in donor 1 and 2

CA-chromosome aberrations; ${ }^{*}-\mathrm{P}<0.05 ;{ }^{* *}-\mathrm{P}<0.01 ;{ }^{* *}-\mathrm{P}<0.001$ EMS - ethyl methanesulfonate used as a positive control

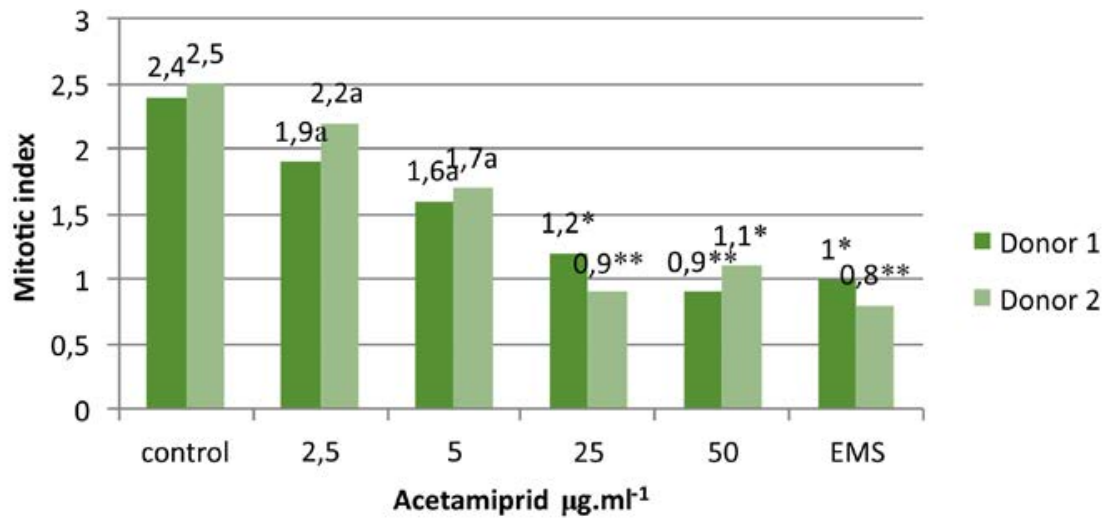

Fig. 2. Decrease in mitotic index with increasing concentration of acetamiprid

${ }^{*}-\mathrm{P}<0.05 ;{ }^{* *}-\mathrm{P}<0.01 ;$ EMS - ethyl methanesulfonate used as a positive control 


\section{DISCUSSION}

Cattle are used in experiments as a bioindicator of environmental pollution for their rearing method and feed intake. During grazing, they are directly exposed to substances found in the environment, consuming high amounts of feed per day that have undergone chemical treatment with insecticides and can be exposed to wastewater [8]. In contrast to other domestic animals, such as rats and humans, cattle have the lowest biotransformation ability of xenobiotics in the liver [16]. At present, there are not many studies with acetamiprid that would focus on its action on cattle. The study by Seccia et al. [14] focused on the detection of four pesticides (acetamiprid, imidacloprid, thiacloprid and thiamethoxam) in cow's milk. The study revealed residues in the bovine milk being equal to or lower than the maximum residue limit established by the European legislation [14].

In male Kunmin mice, the effect of acetamiprid on the physiological functions of their reproductive apparatus and the effect of oxidative stress on the testes were investigated. The results showed that the application of acetamiprid significantly reduced the body weight of the mice as well as the weight of their organs such as testes, epididymis and prostate. Furthermore, serum testosterone concentration and sperm quality and quantity were affected [17]. In the study of mouse sperm abnormalities following intraperitoneal administration of acetamiprid and propineb together as well, acetamiprid did not significantly increase the percentage of abnormal sperm after 24 or $48 \mathrm{~h}$ exposure [12]. In female rats after oral administration of acetamiprid at $200 \mathrm{mg} \cdot \mathrm{kg}^{-1}$, the total leukocyte count and the relative lymphocyte count together with globulins were significantly reduced $(\mathrm{P}<0.01)$ [10].

The aim of the in vitro study in human lymphocytes was to investigate the effects of water-soluble fullerene nanoparticles on acetamiprid-induced genotoxicity. Cultured human lung fibroblasts were exposed to fullerenol alone and together with acetamiprid for $24 \mathrm{~h}$. The results demonstrated significantly induced micronucleus formations and single- or double-stranded DNA breaks in IMR90 cells after exposure to acetamiprid [3].

Another study focused on the effect of acetamiprid, probineb and their combination in peripheral lymphocytes in humans. The data pointed to a possible synergistic effect of both pesticides with cytotoxic effects and potential genotoxic effect in peripheral lymphocyte [11].
In the second part of our study, we used fluorescence in situ hybridization (FISH) and focused on the detection of stable chromosomal aberrations, which cannot be assessed by conventional cytogenetic methods. We used whole chromosome probes BTA 1 and BTA 7 on chromosomes 1 and 7. In the experiment two polyploidies were observed and neither reciprocal nor non-reciprocal translocations were recorded. This may be due to the insufficient amount of probes used and thus does not capture enough genome.

\section{CONCLUSIONS}

Our results obtained by conventional cytogenetic analysis showed elevation in chromosome aberrations (mainly chromosome and chromatid breaks) after exposure to acetamiprid compared to negative control. With increasing concentration, we could observe a decrease in mitotic activity. Based on our results, we can assume possible genotoxic effects of acetamiprid on the chromosomes of cattle.

\section{ACKNOWLEDGEMENTS}

The Ministry for Education and Science of the Slovak Republic supported this study under contracts IGA 09/2017, VEGA 1/0176/16 and VEGA 1/0242/19.

\section{REFERENCES}

1. Boffetta, P., Van Der Hel, O., Norppa, H., Fabianova, E., Fucic, A., Gundy, S., et al., 2006: Chromosomal aberrations and cancer risk: Results of a cohort study from central Europe. Am. J. Epidemiol., 165, 1, 36-43. DOI: 10.1093/aje/kwj367.

2. Bryant, P. E., 1998: The signal model: a possible explanation for the conversion of DNA double-strand breaks into chromatid breaks. Int. J. Radiat. Biol., 73, 3, 243-251.

3. Çavaş, T., Çinkılıç, N., Vatan, Ö., Yılmaz, D., 2014: Effects of fullerenol nanoparticles on acetamiprid induced cytotoxicity and genotoxicity in cultured human lung fibroblasts. Pestic. Biochem. Physiol., 114, 1-7. DOI: 10.1016/j.pestbp. 2014.07.008

4. Cohen, M., 2007: Environmental toxins and health: the health impact of pesticides. Aust. Fam. Physician, 36, 12, 1002-1004. 
5. Doublet, V., Labarussias, M., de Miranda, J. R., Moritz, R. F., Paxton, R. J., 2015: Bees under stress: sublethal doses of neonicotinoid pesticide and pathogens interact to elevate honey bee mortality across the life cycle. Environ. Microbiol., 17, 4, 969-983. DOI: 10.1111/1462-2920.12426.

6. Douglas, M.R., Rohr, J.R., Tooker, J.F., 2015: Editor's choice: Neonicotinoid insecticide travels through a soil food chain, disrupting biological control of non-target pests and decreasing soya bean yield. J. Appl. Ecol., 52, 1, 250-260. DOI: $10.1111 / 1365-2664.12372$.

7. Kopp, B., Vignard, J., Mirey, G., Fessard, V., Zalko, D., Le Hgarat, L., Audebert, M., 2018: Genotoxicity and mutagenicity assessment of food contaminant mixtures present in the French diet. Environ. Mol. Mutagen., 59, 8, 742-754. DOI: 10.1002/em.22214.

8. Losada, A., Fernández, N., Diez, M. J., Terán, M. T., García, J. J., Sierra, M., 1996: Organochlorine pesticide residues in bovine milk from Leon (Spain). Sci. Total Environ., 181, 2, $133-135$

9. Marrs, T. C., 2012: Toxicology of insecticides to mammals. Pest Manag. Sci., 68, 10, 1332-1336. DOI: 10.1002/ps.3362.

10. Mondal, S., Ghosh, R.C., Mate, M.S., Karmakar, D.B., 2009: Effects of acetamiprid on immune system in female wistar rats. Proceedings of the Zoological Society, 62, 2, 109-117.

11. Muranli, F. D. G., Rasgele, P. G., Kekecoglu, M., Kanev, M., Ozdemir, K., 2015: Potential genotoxicity of acetamiprid and propineb singly or in combination in cultured human peripheral blood lymphocytes by using MM assay. Fresen. Environ. Bull., 24, 11B, 3947-3955.
12. Rasgele, P. G., 2014: Abnormal sperm morphology in mouse germ cells after short-term exposures to acetamiprid, propineb, and their mixture. Arh. Hig. Rada Toksikol., 65, 1, 47-56. DOI: 10.2478/10004-1254-65-2014-2408.

13. Savage, J. R., 1998: A brief survey of aberration origin theories. Mutat. Res., 404, 1-2, 139-147.

14. Seccia, S., Fidente, P., Montesano, D., Morrica, P., 2008: Determination of neonicotinoid insecticides residues in bovine milk samples by solid-phase extraction clean-up and liquid chromatography with diode-array detection. J. Chromatogr. A, 1214, 1-2, 115-120. DOI: 10.1016/j.chroma.2008.10.088.

15. Simon-Delso, N., Amaral-Rogers, V., Belzunces, L. P., Bonmatin, J. M., Chagnon, M., Downs, C., et al., 2015: Systemic insecticides (neonicotinoids and fipronil): trends, uses, mode of action and metabolities. Environ. Sci. Poll. Res. Int., 22, 1, 5-34. DOI: 10.1007/s11356-014-3470-y.

16. Watkins III, J. B., Klaassen, C. D., 1986: Xenobiotic biotransformation in livestock: comparison to other species commonly used in toxicity testing. J. Anim. Sci., 63, 3, 933-942.

17. Zhang, J. J., Yi, W. A.N. G., Xiang, H. Y., Li, M.X., Li, W.H., Wang, X. Z., Zhang, J.H., 2011: Oxidative stress: role in acetamiprid-induced impairment of the male mice reproductive system. Agric. Sci. China, 10, 5, 786-796.

Received February 15, 2019

Accepted May 29, 2019 